\title{
The Determinants of purchasing the Charged Contents in the Smart-media environment
}

\author{
Changjun LEE*, Ahreum HONG*, Junseok HWANG* \\ * Technology Management, Economics, and Policy Program \\ Seoul National University, Korea \\ changjun.chris.lee@gmail.com, ahreumhong00@gmail.com,junhwang@snu.ac.kr
}

\begin{abstract}
It is important that improving the value of contents felt by consumers and inducing settlement of healthy culture of consuming the charged contents in order to enhance the global competitiveness of contents industry. Korea has gotten into the smart-media era very rapidly, however, many consumers are still reluctant to purchase the charged contents. This research aims to analyse which factors have an effect on purchasing the charged contents in the view of consumers' device selection, innovativeness, and lifestyle. The results show that consumers who use smart-pad, who cognize the value of content high, and who has a role of opinion leader are likely to purchase charged contents. In addition, after considering the sample selection bias, factors to purchase charged content appears differently by types of contents; application, broadcast, news media, video, music, etc. This paper is able to provide some clues to promoting contents industry macroscopically for the policy makers.
\end{abstract}

Keywords - charged-contents, factor analysis, smart-media, sample selection bias, contents industry

\section{INTRODUCTION}

Every day, we are getting to know about the world interacting with contents, especially by smart-device like smart-phone or smart-pad, a platform that consume a lot of contents and able to be optimized by customers. As the consumption of the contents by smart-device increases, the industry boundaries between content, network, device, and platform are collapsing [1], [2]. This phenomenon of convergence has changed the paradigm of production and distribution in information and communication technology (henceforth ICT), and caused the big change of the media consumption behaviour of consumers.

To promote domestic content industry, the number of people who not only understand the difficulty and the risk of producing contents but also have a will to give credit for the creativity of contents has to be increased. However, expense to the digital contents is hardly increased while the personal cost of smart-device and communication charge is increased [3]. There are two reasons why expense to digital contents has to be increased. Firstly, it needs to improve the value of the digital contents felt by consumers for promoting the contents industry. Many contents providers choose the strategy of making profit, not being compensated by the content itself but giving the contents freely and being compensated by advertisements. However, since this indirect profit structure consistently brings down the value of contents felt by consumers, thereby it is implausible to expect sustainable profit from it. Second reason is for nurturing the global competitiveness of domestic content industry. Since global media market in the future would make the contents trade beyond the national boundary possible, domestic contents industry has to reduce the dependency of the terrestrial contents and expand to the global contents. This is possible when the healthy culture of consuming the charged contents is settled well.

Then, why some consumers purchase the charged contents willingly while others don't? This paper starts from the above question. Through KISDI Media panel 2012 statistics, the ratio of the people who have used the charged application at least once is $12.56 \%$. It is still low comparing with the ratio of the smart-phone user which is $54.43 \%$. Contrary to initial expectations which overall ICT ecosystem (Content - Platform - Network - Device) will show greater vitality with diffusion of smart-device, the charged contents are still considered too burden for consumers and get low willingness to pay. Therefore, the goal of this paper is analysing which factors effect on purchasing the charged contents for consumers. This paper also analyse which characteristics of consumers increase the willingness to pay if they buy the charged contents, 
and if the categories of contents differ what main difference is. This paper starts to research just about the relationship between the media consumption behaviour and purchasing the charged contents. However, the further studies will be possible to give the marketing implication to the contents providers and provide some clues to promoting contents industry macroscopically for the policy maker.

\section{LITERATURE REVIEW}

\section{A. The factor of using smart-device}

According to the Agarwal and Prasad (1998) and Zhong (2013), ICT innovativeness of consumer is measured by whether they use the newest mobile media device or not. Nowadays, the newest mobile media device is smart-device like smart-phone or smart-pad since it performs a bridging role to change the usage from doing their business through the device like PC with internet to using the device for leisure and entertainment mainly. In addition, through smart-TV, smart-phone, or smart-pad, consumers experience the expanding ability consuming media contents by their smart-devices. Smart-devices help the consumers, who choose to use it, evolve to the advanced user group and the characteristics of this group effect on the frequency of using the charged contents and purchasing behaviour.

\section{B. On the perspective of user's innovativeness}

Need for cognition (NFC) is an important factor for identifying an individual's propensity to use the information, materials and techniques and it is easy to measure the scale [6]. Zhong (2013) determines the innovativeness of user using NFC. Cacioppo, Petty, and Feng Kao (1984) and Zhong (2013) use the questionnaire of NFC like "It is not funny that is not from my idea", "I use a lot of time to explore my favorite things". It means that this scale is about how much they feel happy when they explore the information they want. It might be possible to make some bias if we measure the personal innovativeness from direct questionnaire; thereby it needs NFC factor to determine the real behaviour pattern.

\section{On the perspective of the information producer}

According to Brandtzæg et al. (2011), Information producers are able to be categorized into two groups; network user, who communicate with family or co-workers and real network group through internet, and advanced user who use the internet not only for the leisure or entertainment but for the productive work well. Rogers and Shoemaker (1971) define the innovative user with people whose willingness to take risk for the new product or innovation is high. In addition, Lin (2004) categorize the innovative user with the group choosing the web-casting, Kang (2002) categorize the innovative user with people who adopt to pay broadcasting, which is introduced in 1996. In this paper, we categorize the information producer with people who use the new data storage technology like cloud service and operate own internet café or blog and use social network service (SNS) to share the information.

\section{On the perspective of user's cultural lifestyle}

The entertainment user in Brandtzæg et al. (2011) is a group who evaluate the value of information good and contents high and charge to the culture activity or going to see performances and sports highly. Since this group sets a great deal of weight upon culture activities, they set the equivalent value upon digitalized contents which includes same kind of cultural contents.

\section{DATA}

Data source is from KISDI Media Panel 2010 2012 (3 years). This paper use the 2012 personal data and media diary and it has 10,319 of personal data set, through stratified sampling, considered the distribution of demographics in Korea. Media diary is the information about each person's media behaviour in random straight three days.

\section{METHOD}

\section{A. Probit model}

Firstly, this paper analyse the primary factors of purchasing the charged contents. People usually use their smart-device not only for the voice 
communication but also for the variety applications added on their smart-platform. Therefore this paper let dependent variable with the experience of purchasing the charged application. For independent variables, this paper considers the characteristics and lifestyle of consumers. Main independent variables used in this paper are below table 1. CHAR variables are about personal characteristics and measured using the 5 point lickert is scale. LIFESTY variables are for consumers' lifestyle and CONBEHVs are for consumer behaviour. Probit model, which is econometric method for analysing the factors, is used when the dependent variable appears 1 or 0 , like consumer's selection.

TABLE 1. INDEPENDENT VARIABLES AND EXPLANATIONS

\begin{tabular}{ll}
\hline Variable & Explanation \\
\hline Fre.Phone & Frequency of using smart-phone in a day \\
\hline Fre.Pad & Frequency of using smart-pad in a day \\
\hline CHAR3 & I am spontaneous and free \\
\hline CHAR5 & I am happy when I'm with other people \\
\hline CHAR6 & I like receiving attention \\
\hline CHAR8 & I'm a little emotional changes \\
\hline CHAR9 & I rarely get angry \\
\hline LIFESTY2 & Frequency of social activities \\
\hline LIFESTY4 & Frequency of Religious activities \\
\hline LIFESTY6 & Frequency of going out for performance \\
\hline LIFESTY7 & Frequency of going out for seeing sports \\
\hline CONBEHV1 & It is important whether the latest product or not \\
\hline CONBEHV4 & It is important that the other's reputation in internet \\
\hline CONBEHV5 & Satisfied with minimal features and affordable price is \\
\hline CONBortant
\end{tabular}

\section{B. Heckman's 2SLS Model}

Secondly, through Heckman's 2 stage least square model, this paper corrects the sample selection bias. It makes possible to analyse how much they pay from which factor. Since there are a lot of differences between the group of having purchased the charged contents once and the other group of having not, after correcting the bias of purchasing the charged contents, we carry on the factor analysis including the correcting coefficient. At this time, while dependent variable is also discrete, it has a scale from 0 to their maximum point, like 7 . In this paper, we use six dependent variables following table 2 .

TABLE 2. DEPENDENT VARIABLES AND EXPLANATIONS

\begin{tabular}{lll}
\hline Variable & Explanation \\
\hline $\begin{array}{l}\text { 1st stage } \\
\text { Dependent } \\
\text { variable }\end{array}$ & Exp.chgApp & $\begin{array}{l}\text { Experience whether downloading the } \\
\text { charged application or not }\end{array}$ \\
\hline & Cost.chgApp & $\begin{array}{l}\text { The degree of cost for charged } \\
\text { application }\end{array}$ \\
\cline { 2 - 3 } $\begin{array}{l}\text { 2nd stage } \\
\text { Dependent } \\
\text { variable }\end{array}$ & Cost.book & $\begin{array}{l}\text { The degree of cost for digital news / } \\
\text { magazine / book contents }\end{array}$ \\
\cline { 2 - 3 } & Cost.movie & $\begin{array}{l}\text { The degree of cost for digital video and } \\
\text { movie contents }\end{array}$ \\
\cline { 2 - 3 } & Cost.music & $\begin{array}{l}\text { The degree of cost for digital TV } \\
\text { broadcast program contents }\end{array}$ \\
\cline { 2 - 3 } & Total.Cost & $\begin{array}{l}\text { The degree of cost for digital music } \\
\text { contents }\end{array}$ \\
\hline
\end{tabular}

\section{RESULTS AND ANALYSIS}

\section{A. The factors of purchasing the charged contents (Probit model)}

The results of analysing the factors for purchasing the charged contents are following table 3 . The results can be summarized as the five things. Firstly, the more people who use smart devices, the more one is likely to purchase paid content. Of them, frequency of using smart-pad $(0.051)$ has higher coefficient than smart-phone (0.036). Since using smart-pad is more innovative characteristics (Zhong, 2013), they have high willingness to pay for charged contents.

Secondly, people who like being with other people $(-0.050)$, and the more having friendships with many people $(-0.055)$ are less likely to purchase paid content. Third, people who like to go to see a performance \& culture $(0.061)$, sports (0.075) and the higher frequency of cultural activities they have are likely to purchase paid content. It seems that the group spending on cultural activities has a similar willingness to pay for digitalized contents. 
Fourth, the higher internet reputation the products have (0.078), the more direct buying products which I'll use (0.151) are significantly more likely to purchase paid content. These two items are the attributes for 'Need for cognition' and also one of attributes for determining 'Power user'. Lastly, people who operate a blog (.260) and an internet cafe (.278) and who use social network services $(0.360)$ and cloud services $(0.440)$ more are likely to purchase paid content. Online opinion leader usually want to use the new things [12] and, people who manage own blog or internet café might be a role of opinion leader for selecting the new charged contents on online. Also users who use cloud or social network services represent same results as online opinion leaders.

TABLE 3. THE RESUlT OF FACTOR ANALYSIS (PROBIT MODEL)

\begin{tabular}{crrrl}
\hline & Coefficient & \multicolumn{1}{c}{ Std. Error } & \multicolumn{1}{c}{ P value } & \\
\hline Fre.Phone & 0.036 & $(0.005)$ & 0.000 & $* * *$ \\
\hline Fre.Pad & 0.051 & $(0.025)$ & 0.039 & $*$ \\
\hline CHAR5 & -0.050 & $(0.024)$ & 0.036 & $*$ \\
\hline LIFESTY2 & -0.055 & $(0.016)$ & 0.001 & $* * *$ \\
\hline LIFESTY6 & 0.061 & $(0.017)$ & 0.000 & $* * *$ \\
\hline LIFESTY7 & 0.075 & $(0.021)$ & 0.000 & $* * *$ \\
\hline CONBEHV9 & 0.078 & $(0.030)$ & 0.008 & $* *$ \\
\hline CONBEHV10 & 0.151 & $(0.027)$ & 0.000 & $* * *$ \\
\hline POL6 & -0.063 & $(0.017)$ & 0.000 & $* * *$ \\
\hline BLOG & 0.260 & $(0.070)$ & 0.000 & $* * *$ \\
\hline SNSU & 0.360 & $(0.059)$ & 0.000 & $* * *$ \\
\hline CLOUD & 0.440 & $(0.080)$ & 0.000 & $* * *$ \\
\hline iN.CAFE & 0.278 & $(0.056)$ & 0.000 & $* * *$ \\
\hline AGE & -0.112 & $(0.020)$ & 0.000 & $* * *$ \\
\hline Game & 0.348 & $(0.086)$ & 0.000 & $* * *$ \\
\hline Bank & 0.545 & $(0.164)$ & 0.001 & $* * *$ \\
\hline
\end{tabular}

\section{B. The factors of purchasing the charged contents by the categories of contents (Heckit model)}

Next analysis is about which factors cause consumers charge more to the paid contents by content type. Firstly, CHAR9 is significant with the coefficient of -0.393 , CONBEHV1 is significant with -0.380 , CONBEHV6 is 0.410 . CHAR9 (Rarely get angry) has negative correlation, CONBEHV6 (the most important thing is design or color) has positive correlation, this means that the more people has certain preference, the more he or she is likely to spend the total charged digital contents, this result has something in common with CONBEHV1 (important whether the newest or not) has negative correlation. For that people, the important thing is not just the newest or not, the design or color which he or she likes is much more important. Therefore, it is possible to say the people who express his or her opinion for certain are likely to invest to the charged contents.

Secondly, in the case of charged application, the factor CHAR3 is -0.238 , CHAR6 is 0.273 , CHAR9 is -0.393 , CONBEHV1 is -0.285 , CONBEHV4 is 0.236 , CONBEHV5 is -0.203 , above variables are significant. The person who is not spontaneous and free and rarely gets angry and likes receiving good care is likely to pay for charged application. For the view of consumption behaviour, person who does not care whether the newest product of not, who does care about internet reputation, and who is not satisfied with just minimum function is likely to pay for the charged application. This result is very similar with the above total charged contents, however, since the application content type is not existed before (just emerging with smart-device), the group who are not satisfied with just minimum function but care about the internet reputation, and are not spontaneous but careful consumer, seems to pay for charged application.

Third, for the charged digital contents like news / magazine / e-book, Fre.Phone (0.009), LIFESTY2 (-0.025), CONBEHV10 (0.043), BLOG (0.085), SNSU (0.148), CLOUD (0.161), iN.CAFE (0.102) are significant each. Since the characteristics of news/magazine/book, mobility is important factor for using, thereby representing positive correlation in frequency of using smart-phone. In addition, person who has low social activity but operate blog or internet café or use SNS is likely to pay for the charged digital contents. It means that active social activity in reality is not correlated with online activity and person who has online leadership is likely to purchase the charged digital contents.

Fourth, for the charged digital video or movie contents, Fre.Pad (0.107), LIFESTY4 (0.055), AGE $(-0.056)$ are significant variables. Due to the nature of visual media, using smart-pad is significant, not smart-phone because the screen size of smartdevice is important. Also, as consuming digital video media through smart-device is strange for the middle and old age, the younger the more they pay for digital video / movie content. 
Lastly, for the charged digital broadcast program, Fre.Phone (0.042), Fre.Pad (0.129), CONBEHAV10 (0.207), BLOG (0.405), SNSU (0.518), CLOUD (0.739) are significant variables. In the case of broadcast contents, it is similar with the fourth analysing result because it has also characteristics of visual media contents; therefore the frequency of smart-pad is significant factor. However the frequency of smart-phone is also significant, it means that unlike the movie and video contents, since broadcast contents is very sensitive on time, mobility is important factor for using that kind of contents. In addition, taking the characteristics of media contents like third analysis for news/magazine/book into considering, it is explained for TV broadcast by same manner about why blog and internet café manager and SNS user group are likely to purchase the charged digital broadcast program. Media contents is an information good having time attribute, which is important to know the information before others know and online leadership is from that rare information. Therefore, it is possible to conclude that online opinion leader is likely to purchase the charged TV broadcast contents.

TABLE 4. THE RESULT OF FACTOR ANALYSIS (HECKIT MODEL)

\begin{tabular}{|c|c|c|c|}
\hline \multicolumn{2}{|c|}{ Total charged contents } & Charged application & News/book \\
\hline & Estimate Std. error & Estimate Std. error & Estimate Std. error \\
\hline Fre.Phone & $-0.007 \quad(0.029)$ & $-0.008 \quad(0.020)$ & $0.009(0.003) * *$ \\
\hline CHAR3 & $-0.187(0.147)$ & $-0.238(0.098)^{*}$ & $0.007 \quad(0.021)$ \\
\hline CHAR6 & $0.248(0.148)$ & $0.273(0.099)^{* *}$ & $0.002(0.021)$ \\
\hline CHAR9 & $-0.393(0.156)^{*}$ & $-0.256(0.104)^{*}$ & $0.004 \quad(0.022)$ \\
\hline CONBEHV1 & $-0.380(0.160)^{*}$ & $-0.285(0.107)^{* *}$ & $0.000 \quad(0.022)$ \\
\hline CONBEHV4 & $0.155(0.161)$ & 0.236 (0.108)* $^{*}$ & $0.023 \quad(0.022)$ \\
\hline CONBEHV5 & $-0.274(0.140)$ & $-0.203(0.094)^{*}$ & $0.002(0.020)$ \\
\hline CONBEHV6 & $0.410(0.177)^{*}$ & 0.218 (0.118). & $0.005 \quad(0.025)$ \\
\hline CONBEHV10 & $0.060(0.170)$ & $-0.066(0.116)$ & $0.043(0.021)^{*}$ \\
\hline BLOG & $0.212(0.338)$ & $0.026(0.231)$ & $0.085(0.043)^{*}$ \\
\hline SNSU & $0.238(0.366)$ & $0.102(0.256)$ & $0.148(0.041)^{* * *}$ \\
\hline CLOUD & $-0.581 \quad(0.403)$ & $-0.365 \quad(0.281)$ & $0.161(0.045)^{* * *}$ \\
\hline iN.CAFE & $-0.171 \quad(0.318)$ & $-0.017 \quad(0.219)$ & $0.102(0.038)^{* * *}$ \\
\hline \multirow[t]{3}{*}{ AGE } & $-0.001 \quad(0.154)$ & $0.086(0.105)$ & $-0.056(0.019)^{* *}$ \\
\hline & VOD/Movie & TV broadcast & Music \\
\hline & Estimate Std. error Estir & Std. error & Estimate Std. error \\
\hline Fre.Phone & $0.005(0.010)$ & $0.042(0.014)^{* *}$ & $-0.002 \quad(0.006)$ \\
\hline Fre.Pad & $0.107(0.036)^{* *}$ & $0.129(0.066)^{*}$ & $0.015 \quad(0.022)$ \\
\hline CHAR5 & $0.028(0.049)$ & $-0.087 \quad(0.091)$ & $0.071(0.030)^{*}$ \\
\hline CHAR8 & $-0.030(0.057)$ & $-0.015 \quad(0.108)$ & $0.096(0.035)^{* *}$ \\
\hline LIFESTY4 & $0.055(0.022)^{*}$ & $0.013 \quad(0.042)$ & $0.009 \quad(0.013)$ \\
\hline
\end{tabular}

\begin{tabular}{lcclrl}
\hline LIFESTY7 & $-0.028(0.038)$ & 0.123 & $(0.066)$. & $\mathbf{0 . 0 5 1}$ & $(\mathbf{0 . 0 2 3})^{*}$ \\
\hline CONBEHV10 & $0.046(0.057)$ & $\mathbf{0 . 2 0 7}$ & $(\mathbf{0 . 0 9 7})^{*}$ & $\mathbf{0 . 0 7 4}$ & $(\mathbf{0 . 0 3 4})^{*}$ \\
\hline BLOG & $0.025(0.113)$ & $\mathbf{0 . 4 0 5}$ & $(\mathbf{0 . 1 9 7})^{*}$ & 0.120 & $(0.069)$. \\
\hline SNSU & $0.092(0.120)$ & $\mathbf{0 . 5 1 8}$ & $(\mathbf{0 . 1 8 5})^{* *}$ & 0.054 & $(0.072)$ \\
\hline CLOUD & $-0.251(0.133)$ & $\mathbf{0 . 7 3 9}$ & $(\mathbf{0 . 2 0 5})^{* * *}$ & -0.110 & $(0.080)$ \\
\hline AGE & $-0.026(0.052)$ & -0.143 & $(0.090)$ & -0.040 & $(0.031)$ \\
\hline
\end{tabular}

\section{SUMMARY AND CONCLUSION}

It has been an innovative change of distribution channel of contents in app-store as smart-devices are diffused into many consumers. Therefore, it is important to retain diversity of applications for virtuous circulation in ICT ecosystem. The main driving force of expanding the market share of smart-devices is constructing the application ecosystem from producing contents to being consumed by customers.

However, since the current market size is small, it is hard to protect even copyright. Until breaking the situation of not being able to protect copyright, contents industry cannot be promoted. To the active legal market of contents, it needs to provide and adopt 'A la carte' type service through like video on demand (VOD) and also needs to be diffused for the healthy culture to be consumed the charged contents willingly.

For the further study, defining 'power-user', who consumes the information product in more productive way, is one of the key to give a new power of innovation in New ICT ecosystem(C-P-N$\mathrm{D}$-User). This paper proves that the propensity to consume a charged digital content by what, how much, why, with whom, and by which generation. We believe that this finding and our further study will shed light on the promotion of digital content industry based on user-driven innovation.

\section{ACKNOWLEDGMENT}

This research was funded by the MSIP(Ministry of Science, ICT \& Future Planning), Korea in the ICT R\&D Program 2013

\section{REFERENCES}

[1] Abadie, F., I. Maghiros, and C. Pascu, The Future Evolution of the Creative Content Industries. Joint Research Center of EU, 2008.

[2] Fransman, M., The new ICT ecosystem: Implications for policy and regulation. Cambridge University Press, 2010. 
[3] Agarwal, R. and J. Prasad, "A conceptual and operational definition of personal innovativeness in the domain of information technology", Information systems research, vol. 9(2), p. 204-215, 1998.

[4] Zhong, B., "From smartphones to iPad: Power users' disposition toward mobile media devices", Computers in Human Behavior, vol. 20(4), p. 1742-1748, 2013.

[5] Amichai-Hamburger, Y., "Personality and the Internet", The social net: Human behavior in cyberspace, p. 27-55, 2005

[6] Cacioppo, J.T., R.E. Petty, and C. Feng Kao, "The efficient assessment of need for cognition", Journal of personality assessment, vol. 48(3), p. 306-307, 1984.

[7] Brandtzæg, P.B., J. Heim, and A. Karahasanović, "Understanding the new digital divide-A typology of Internet users in Europe", International journal of human-computer studies, vol. 69(3), p. 123138, 2011.

[8] Rogers, E.M. and F.F. Shoemaker, Communication of Innovations; A Cross-Cultural Approach. 1971

[9] Lin, C.A., "Webcasting Adoption: Technology Fluidity, User'Innovativeness, and Media Substitution", Journal of Broadcasting \& Electronic Media, vol. 48(3), p. 157-178, 2004.

[10] Kang, M.-H., "Digital cable: Exploring factors associated with early adoption", The Journal of Media Economics, vol. 15(3), p. 193-207, 2002.

[11] Leonard-Barton, D., "Experts as negative opinion leaders in the diffusion of a technological innovation", Journal of Consumer Research, p. 914-926, 1985.

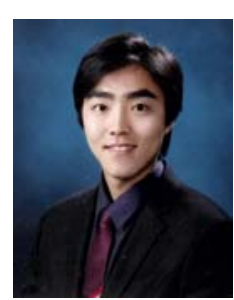

Changjun. LEE is a Ph.D student of technology management of economics and policy program in Seoul national university. He was born at Busan in 1983. In 2002, he graduated Geochang high school and graduated Yonsei university majoring Biology and Chemistry in 2010. He is now at Seoul national university working in smart-media policy center and his research area is policy for promoting the contents and smart-media and content industry.

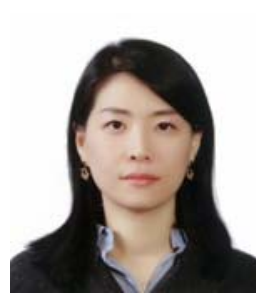

Ahreum Hong is Ph.D in economic and Research Professor at Smart Media Policy Research Center at Techno-Economics, Management, and Policy Program (http://temep.snu.ac.kr) in Seoul National University and also a lecturer in economics at Nam Seoul University. For six years, she also has worked as a researcher of CPRC (Communications Policy Research Center) program that is managed by the KCC (Korea Communications Commission), South Korea. This work is about the regulation and policy research of Korea ICT.

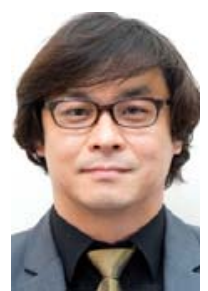

Junseok Hwang is a professor at Technology Management, Economics, and Policy Program (http://temep.snu.ac.kr) in Seoul National University. He is also a chief of at Smart Media Policy Research Center in Seoul Nationa University. For last 10 years, he had served for the director of Communications Policy Research Center and principal professor of International IT Policy Program at Seoul National University.

He obtained B.S. in Mathematics at Yonsei University, Master's Degree in Telecommunications at University of Colorado and his Ph.D in Information Science and Telecommunications at University of Pittsburgh. He had taught at Syracuse University as an assistant professor for three years before taking current position at Seoul National University. His main research field consists Network Economics, Technological Innovation in ICT, Convergence Policy, and so forth. 